\title{
PENGEMBANGAN SISTEM INFORMASI BERBASIS ANDROID DAN DESKTOP PADA RESTORAN SUSHI ZEN RAMEN
}

\author{
R. Fahmi Permadi Achmad', Toni Arifin² \\ ${ }^{1}$ Universitas Adhirajasa Reswara Sanjaya \\ e-mail: permadifahmi@gmail.com \\ ${ }^{2}$ Universitas Adhirajasa Reswara Sanjaya \\ e-mail: toni.arifin@ars.ac.id
}

\begin{abstract}
Abstrak
Ditengah kesibukan restoran yang dibanjiri pengunjung, restoran yang baik adalah restoran yang mampu meningkatkan dan mempertahankan kualitasnya, baik itu dari kualitas rasa makanan, kenyamanan, pelayanan, keamanan, dan pengelolaan. Pengembangan Aplikasi Sistem Informasi adalah salah satu solusi yang mampu mengatasi permasalahan yang ada di restoran. Tujuan dari penelitian ini adalah untuk memudahkan pihak restoran dalam pengoperasian aplikasi dengan dibuatkannya dua aplikasi dengan platform yang berbeda yaitu aplikasi desktop dan mobile yang sesuai dengan kebutuhan user, dan menambahkan beberapa fitur pada aplikasi agar dapat menunjang operasional restoran, penelitian ini dilakukan pada Restoran Sushi Zen Ramen yang berlokasi di daerah Bandung, Jawa Barat. Metodologi digunakan dalam merancang sistem informasi adalah metode Waterfall. Pengumpulan data yang dilakukan berdasarkan tinjauan studi. Pada penelitian ini penulis berhasil membangun dua aplikasi yang saling terhubung, aplikasi desktop yang dibangun menggunakan RAD Studio 10.3 dengan bahasa pemograman Delphi, dan aplikasi android yang dibangun menggunakan Android Studio 3.5.3, dengan bantuan API yang dibuat menggunakan framework SLIM, dan database menggunakan SQLite dan MySql. Aplikasi ini terdiri dari menu master, setting, transaksi, dan laporan serta dilengkapi dengan berbagai macam fitur. Dengan adanya pengembangan sistem ini, pemilik restoran dan manager dapat mengawasi dan mengatasi permasalahan yang dihadapi dalam meningkatkan kualitas restoran.
\end{abstract}

Kata Kunci : Aplikasi Restoran, RAD Studio, Delphi, Aplikasi Android, Sushi Zen Ramen.

\begin{abstract}
Amid the bustle of restaurants flooded with visitors, a good restaurant is a restaurant capable of improving and maintaining its quality, be it from the quality of food flavor, convenience, service, security, and management. The Development of Information System Application is one solution capable of overcoming existing problems in restaurants. The purpose of the study was to facilitate the restaurant party in operation of the application by making it two applications with different platforms namely desktop and mobile applications that suited the user's needs, and added some features to the application in order to support the restaurant's operational, the study was conducted on the Sushi Zen Ramen Restaurant located in the Bandung, West Java area. Methodology used in designing information systems is the Waterfall method. Data collection conducted based on study review. At this study the author successfully built two interconnected applications, a desktop application built using RAD Studio 10.3 with the Delphi programming language, and an android application built using Android Studio 3.5.3, with the help of an API created using the SLIM framework, and a database using SQLite and MySql. The application consists of master menus, settings, transactions, and reports as well as equipped with a wide variety of features. In the presence of development of this system, restaurant owners and managers can oversee and address the problems faced in improving the quality of restaurants
\end{abstract}

Keyword: Restaurant Application, RAD Studio, Delphi, Android Application, Sushi Zen Ramen. 


\section{Pendahuluan}

Pada zaman serba canggih ini, kita diharuskan untuk mengikuti perkembangan teknologi dan informasi, oleh karena itu kita harus dapat mengolah data sehingga menjadi informasi yang bermanfaat secara efektif dan efisien.Teknologi Informasi perlu diterapkan di suatu sistem agar dapat menyajikan informasi secara cepat dan relevan. Salah satunya adalah sistem yang ada di restoran.

Restoran adalah sebuah tempat usaha komersial yang kegiatan di dalamnya menyediakan hidangan makanan dan minuman untuk pengunjung yang bersifat umum (Rakhmah et al., 2019). Ketika restoran sedang sibuk atau ramai pengunjung memungkinkan restoran tersebut menghadapi masalah pelayanan, diantaranya keterlambatan pemesanan menu, kesalahan pencatatan pemesanan menu, dan kesalahan dalam transaksi pembayaran (Febriyansyah et al., 2017). Dengan adanya aplikasi sistem informasi, diharapkan dapat membantu pemilik restoran dalam mengontrol semua kegiatan dan para pegawai meningkatkan pelayananya terhadap pelanggan.

Hutahaean $(2015,15)$ menyimpulkan bahwa "Sistem Informasi adalah suatu sistem didalam suatu organisasi yang mempertemukan kebutuhan pengelolaan transaksi harian, mendukung operasi, bersifat manajerial, dan kegiatan strategi dari suatu organisasi dan menyediakan pihak luar tertentu dengan laporan-laporan yang dibutuhkan".

Restoran Sushi Zen Ramen yang berlokasi di daerah Bandung Jawa Barat menyediakan berbagai macam variasi makanan dan juga minuman. Sejauh ini rumah makan tersebut masih menggunakan sistem pelayanan secara manual dalam pelayananya terhadap konsumen, dan belum menggunakan sistem aplikasi dalam pelayananya. Masalah yang sering dihadapi ketika pembeli akan memesan menu yang dipesannya adalah pembeli harus menunggu cukup lama untuk dilayani dikarenakan keterbatasannya pelayannya (Sofyan et al., 2019)

Sistem restoran Sushi Zen Ramen masih menerapkan sistem pemesanan dengan cara manual, setiap pelayan hsarus mencatat pesanan pengunjung, kemudian pelayan tersebut menyerahkan catatan tersebut ke bagian dapur. Hal ini akan menimbulkan masalah ketika kondisi restoran ramai oleh pengunjung, sehingga membutuhkan tenaga kerja yang lebih. Oleh sebab itu, pengembangan aplikasi sistem informasi sangat diperlukan agar dapat mengatasi semua masalah yang ada (Sofyan et al., 2019).

Penelitian sebelumnya yang dilakukan oleh Sofyan menghasilkan sebuah aplikasi pemesanan makanan dan minuman berbasis mobile android, yang di dalamnya berisikan fitur untuk mengelola data makanan, minuman, dan desert dan ada juga fitur transaksi order (2019).

Penelitain lainnya yang dilakukan oleh Arisantoso (2019) yang berjudul "Pembuatan Sistem Informasi Restoran Berbasis Desktop Mengunakan Framework Bunifu" yang menghasilkan sistem informasi restoran berbasis desktop menggunakan framework Bunifu,

Pada penelitian ini penulis mencoba untuk mengembangkan aplikasi sistem informasi restoran berbasis android dan desktop yang di dalamnya mencakup mulai dari pemesanan, status pesanan konsumen, status meja yang tersedia, transaksi penjualan, transaksi pengeluaran biaya, laporan keuangan, laporan penjualan, dan laporan rangking penjualan menu.

Aplikasi android dibuat dengan menggunakan Android Studio 3.5.3 yang isinya adalah semua yang berhubungan dengan pelayanan, untuk aplikasi berabasis desktopnya dibuat menggunakan RAD 10.3 dengan bahasa pemograman Delphi yang isinya adalah pengelolaan akses pengguna, transaksi yang berhubungan dengan keuangan, dan laporan - laporan. Sedangkan DBMS (Databases Management System) yang digunakan adalah MySQL untuk penyimpanan global, dan dengan SQLite untuk penyimpanan lokal. Adapun framework PHP yang digunakan untuk menghubungkan agar aplikasi android dapat terhubung dengan database MySql yaitu SLIM. Diharapkan dengan menggunakan aplikasi ini dapat menjadi solusi semua permasalahan yang ada.

Menurut Setiawan (2017) Sistem Operasi adalah sebuah program yang bertindak sebagai perantara (interface) antara pemakai komputer (user) dengan komputer (perangkat keras).

Android merupakan salah satu sistem operasi yang paling banyak digunakan oleh pengguna smartphone di 
Indonesia, dalam laporannya pada bulan April 2017 Android digunakan 79.98\% oleh pengguna smartphone di Indonesia (Junianto \& Zuhdi, 2018).

Delphi adalah Lingkungan

Pengembangan Terpadu - Integrated Development Environment (IDE) untuk mengembangkan aplikasi berbasis desktop, web ataupun mobile. Saat ini perkembangan delphi sudah mampu mendukung berbagai macam platform seperti Windows, macOS, iOS, Android, dan Linux. Versi terbarunya saat ini adalah RAD Studio 10.4 Sydney (embarcadero.com, 2020).

Menurut developer.android.com (2020) Android Studio adalah Lingkungan Pengembangan Terpadu (Integrated Development Environment/IDE) resmi untuk pengembangan aplikasi Android, yang didasarkan pada IntelliJ IDEA.

Slim adalah kerangka kerja mikro PHP yang membantu para programmer dengan cepat menulis aplikasi web dan API yang sederhana namun kuat. Pada intinya, Slim adalah operator yang menerima permintaan HTTP, menjalankan rutinitas panggilan balik yang sesuai, dan mengembalikan respons HTTP (Lockhart et al., 2020)

Menurut Unit Laboratorium Fakultas IImu Terapan (2017) SQLite merupakan database yang berukuran kecil, berdiri sendiri, bukan database client server, tanpa konfigurasi namun mempunyai fitur penuh perintah SQL.

Menurut edel.staff.unja.ac.id (2016) MySQL merupakan database engine atau server database yang mendukung bahasa database pencarian SQL. MySQL adalah sebuah perangkat lunak sistem manajemen basis data SQL atau DBMS yang multithread, multi-user. MySQL AB membuat MySQL tersedia sebagai perangkat lunak gratis dibawah lisensi GNU General Public License (GPL), tetapi mereka juga menjual dibawah lisensi komersial untuk kasus-kasus dimana penggunaannya tidak cocok dengan penggunaan GPL.

\section{Metode Penelitian}

Metode Pengembangan Sistem yang dipilih oleh penulis adalah metode Waterfall. Metode Waterfall merupakan suatu metode dalam pengembangan perangkat lunak yang prosesnya berurutan, di mana proses pengerjaannya terus mengalir dari atas ke bawah (seperti air terjun) melewati fase-fase
Requirements (analisis kebutuhan), Design (perancangan dan pemodelan), Implementation (penerapan), Verification (pengujian), dan Maintenance (pemeliharaan) (Sofyan et al., 2019).

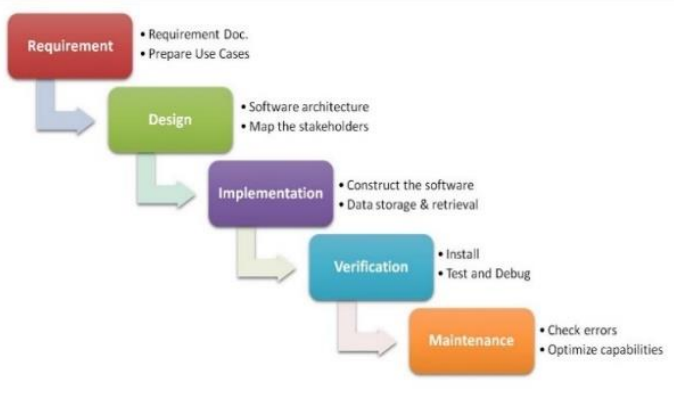

Gambar 1. Waterfall

Sumber : (Sofyan et al., 2019)

1. Requirement (Analisis kebutuhan).

Langakah ini merupakan analisa terhadap kebutuhan sistem. Pengumpulan data dalam tahap ini bisa melakukan sebuah penelitian, wawancara atau studi literatur. Seseorang peneliti akan menggali informasi sebanyak banyaknya dari pengguna sehingga akan tercipta sebuah aplikasi/ program yang bisa melakukan tugas-tugas yang diinginkan oleh pengguna tersebut.

\section{Design (Disain/ Rancangan)}

Proses Design akan menterjemahkan syarat kebutuhan ke sebuah perancangan perangkat lunak yang dapat diperkirakan sebelum diimplementasikan. Proses ini berfokus pada Detail Prosedural (flowchart \& Diagram), arsitektur perangkat lunak, representasi interface.

3. Implementation (Penerapan)

Penggunaan komputer akan dimaksimalkan dalam tahapan ini. Yaitu tahapan dimana keseluruhan desain diubah menjadi kode-kode program. kode program yang dihasilkan masih berupa modul-modul yang selanjutnya akan di integrasikan menjadi sistem yang lengkap untuk meyakinkan bahwa persyaratan perangkat lunak telah dipenuhi.

4. Verification (Integrasi \& pengetesan)

Tahapan ini bisa jadi dikatakan sebagai final dalam proses pembuatan sebuah sistem. Yaitu tahap verifikasi oleh pengguna. Pengguna akan menguji apakah aplikasi yang telah dibuat tersebut telah sesuai dengan keinginan pengguna. Tahapan ini adalah final dalam pembuatan program, tapi bukan pada metode pengembangan program. 


\section{Maintenance (Pemeliharaan)}

Tahap akhir pengembangan sistem pada model Waterfall adalah pemeliharaan yang termasuk diantaranya instalasi dan proses perbaikan sistem sesuai dengan keinginan pengguna atau yang sesuai dengan kontrak kerja.

Seiiring berjalannya waktu dan semakin berkembangnya zaman maka kebutuhan user pada aplikasi sistem informasi juga akan semakin meningkat, agar aplikasi tersebut dapat mengikuti perkembangan yang terjadi. Oleh karena itu diperlukan kegiatan menganalisa kebutuhan sistem yang tujuannya untuk mengembangkan kembali aplikasi agar mampu memenuhi semua yang dibutuhkan user. Hal ini dilakukan untuk menghasilkan aplikasi yang lebih baik dari segi antar muka, performa, keamanan, dan fitur. Sehingga dapat meningkatkan kualitas restoran tersebut.

Sistem ini akan dibuatkan menjadi dua aplikasi dengan platform yang berbeda dalam satu basis data yang sama yaitu MySql. Aplikasi berbasis desktop dengan platform Windows yang dapat digunakan di sebuah $P C$ atau laptop di dalamnya terdapat menu untuk kebutuhan kasir, manager, dan pemilik. Berikut adalah menu yang akan ditambahkan pada aplikasi berbasis desktop: 1. Kelola User

Menu ini digunakan oleh pengguna yang memiliki akses untuk menambahkan user atau mengatur hak akses pengguna lain.

\section{Data Meja}

Menu ini masuk ke kelompok menu master, yang berfungsi untuk menambahkan, merubah, atau aktivasi data meja.

\section{Data Menu}

Menu ini masuk ke kelompok menu master, yang berfungsi untuk menambahkan, merubah, atau aktivasi data menu (makanan dan minuman).

\section{Data Kas \& Bank}

Menu ini masuk ke kelompok menu master, yang berfungsi untuk menambahkan, merubah, atau aktivasi data kas \& bank yang digunakan pada saat transaksi.

\section{Setting Harga}

Menu, menu ini masuk ke kelompok menu setting, yang berfungsi untuk mengatur harga menu yang akan ditampilkan pada saat transaksi.

\section{Faktur Jual}

Menu ini masuk ke kelompok menu transaksi, Kasir dapat membuat faktur jual berdasarkan pesanan dari pelanggan yang makan ditempat, atau tidak berdasarkan pesanan (untuk pembeli yang makanan dan minumannya dibawa pulang).

7. Pengeluaran Biaya

Menu ini masuk ke kelompok menu transaksi, transaksi ini berfungsi sebagai pencatat pengeluaran uang dari kas atau bank, yang nantinya berpengaruh terhadap saldo keuangan.

\section{Penerimaan Pendapatan}

Menu ini masuk ke kelompok menu transaksi, transaksi ini berfungsi sebagai pencatat penerimaan uang yang masuk ke kas atau bank, yang nantinya berpengaruh terhadap saldo keuangan.

9. Mutasi Kas \& Bank

Menu ini masuk ke kelompok menu laporan, laporan ini nantinya menampilkan rincian pengeluaran, pendapatan, dan saldo yang ada di masing - masing kas dan bank.

10. Laporan Penjualan

Menu ini masuk ke kelompok menu laporan, laporan ini menampilkan informasi mengenai penjualan.

11. Laporan Ranking Penjualan

menu ini masuk ke kelompok menu laporan, laporan ini menampilkan informasi ranking penjualan berdasarkan menu yang terjual, atau nilai penjualan dalam periode terpilih.

Sedangkan aplikasi dengan platform Android yang dapat digunakan di sebuah smartphone atau tablet, yang di dalamnya terdapat menu untuk kebutuhan pelayan dan koki. Berikut adalah rancangan menu yang ditambahkan pada aplikasi android :

1. Data Menu

Menampilkann list menu makanan dan minuman, user hanya dapat merubah status ketersediaan menu tersebut.

\section{Status Meja}

Menampilkann daftar status meja, sehingga calon pelanggan dapat melakukan reservasi terlebih dahulu, atau pelayan dapat mengarahkan pengunjung langsung ke meja yang masih kosong.

3. Status Dapur

Menampilkann status pesanan pelanggan berdasarkan waktu pesannya, sehingga pelayan atau koki dapat mengontrol siapa yang lebih dulu diproses pesanannya dengan mudah. 


\section{Transaksi Order}

Menu ini diinput ketika pelanggan sudah memutuskan pilihan menu yang akan dipesannya.

Untuk keamanan informasi dan kenyamanan dalam pemakaian aplikasi, maka diperlukannya hak akses untuk setiap menu dan fitur yang dapat digunakan oleh user sesuai dengan kebutuhannya. Oleh karena itu sistem akan membatasi penggunaannya berdasarkan diagram use case berikut:

\section{Use Case Diagram Aplikasi Desktop}

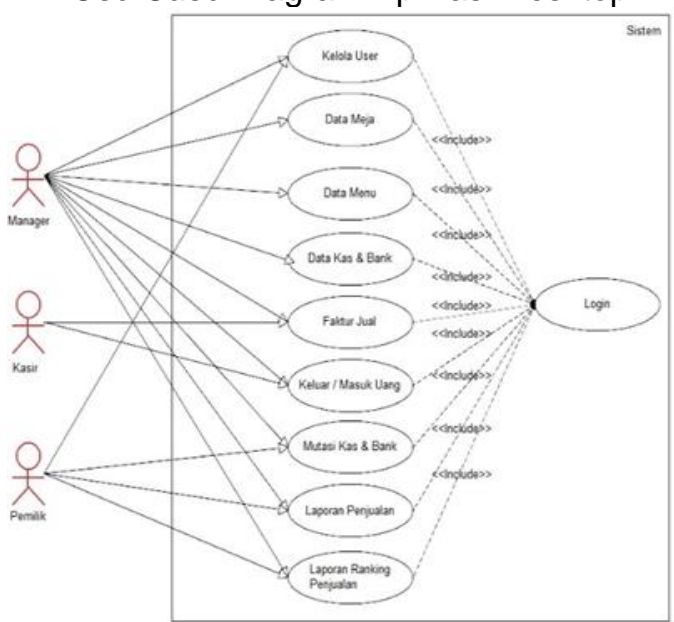

Gambar 2. Use Case Diagram Aplikasi Desktop

2. Use Case Diagram Aplikasi Android

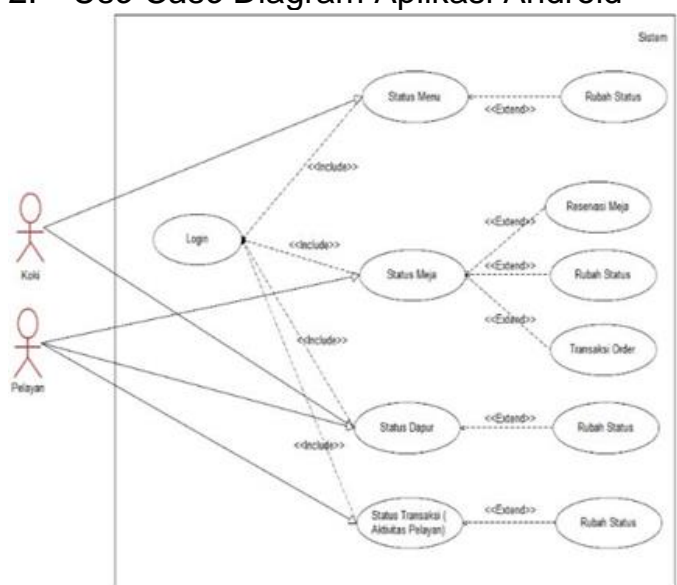

Gambar 3. Use Case Diagram Aplikasi Android

\section{Hasil dan Pembahasan}

Bagian ini berisikan mengenai implementasi sistem, hasil pengujian sistem dan kesimpulan dari pengujian sistem.

\subsection{Implementasi Sistem}

Tahapan ini merupakan tahapan yang paling penting, yaitu penerapan aplikasi yang telah dirancang terhadap sistem yang berjalan.
Pada tahapan ini kita dapat menilai apakah aplikasi sudah sesuai dengan kebutuhan user atau belum.

\section{Aplikasi Desktop}

1. Menu Utama menampilkan menu - menu yang dapat diakses oleh pengguna yang melakukan login.

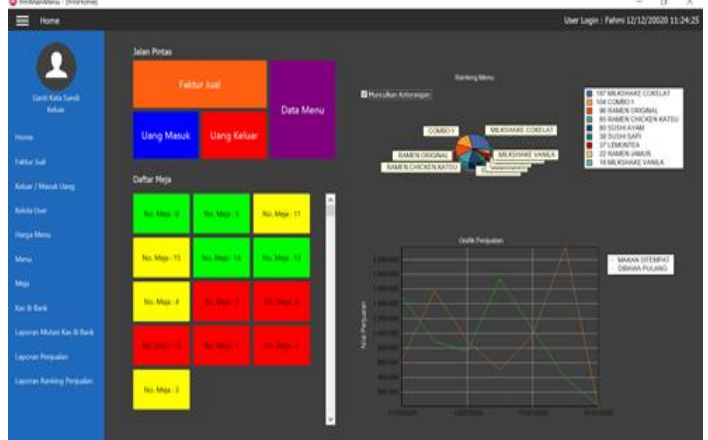

Gambar 4. Form Menu Utama Aplikasi Desktop

2. Setting Harga Menu berfungsi untuk mengisi atau merubah harga menu makanan dan minuman yang sedang aktif, sehingga pada saat kasir menginput faktur jual maka harga menu akan terisi otomatis sesuai harga yang berlaku.

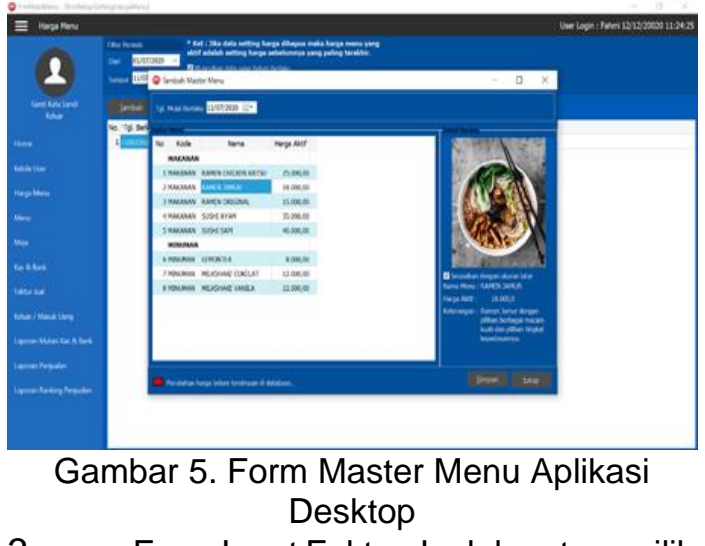

3. Form Input Faktur Jual dapat memilih berdasarkan pesanan dari pengunjung yang makan ditempat atau pengunjung yang pesanannya dibawa pulang.

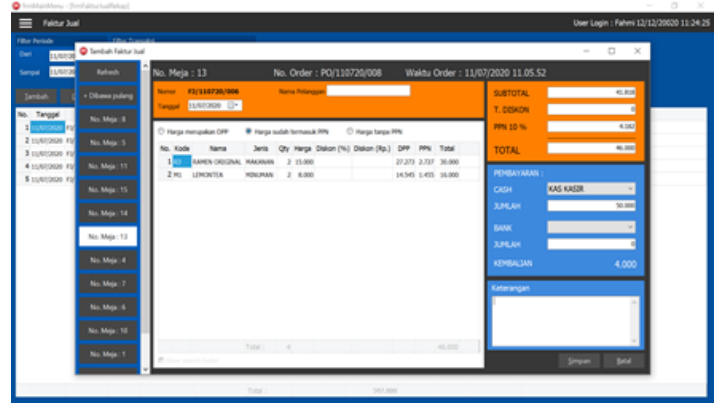

Gambar 6.Form Faktur Jual Aplikasi Desktop 
4. Laporan Mutasi Kas Bank menampilkan informasi sesuai filter ketika tombol load diklik. Menu ini menampilkan rincian penggunaan dana dan saldo akhir dari setiap akun kas / bank.

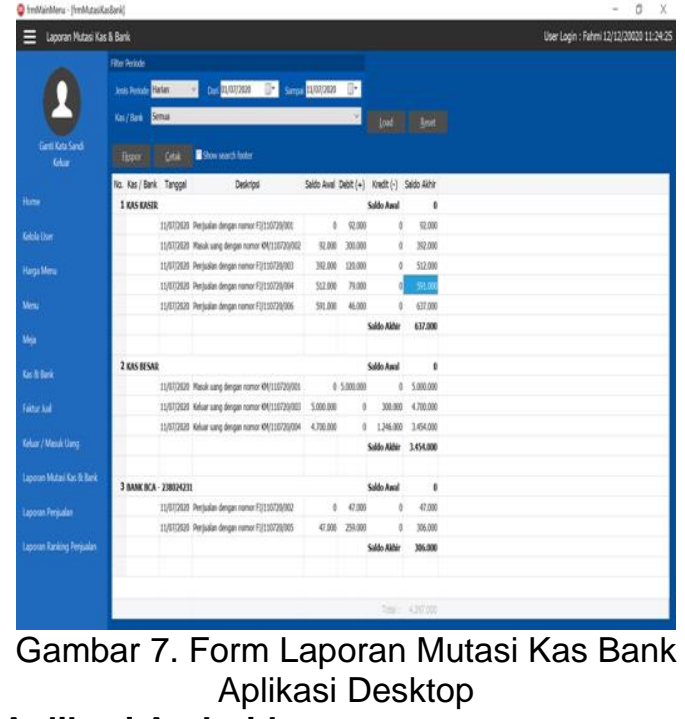

Aplikasi Android

1. Menu Utama adalah tampilan pertama kali ketika user berhasil melakukan login

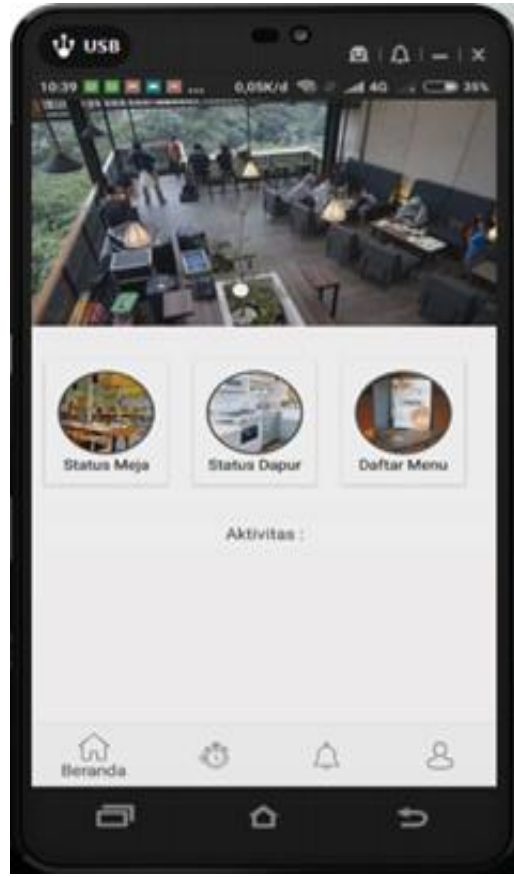

Gambar 8. Form Menu Utama Aplikasi Android

2. Status Meja menampilkan semua data meja yang aktif. Dalam membedakan status meja sistem memberikan beberapa warna agar memudahkan user.sistem memberikan beberapa warna agar memudahkan user.

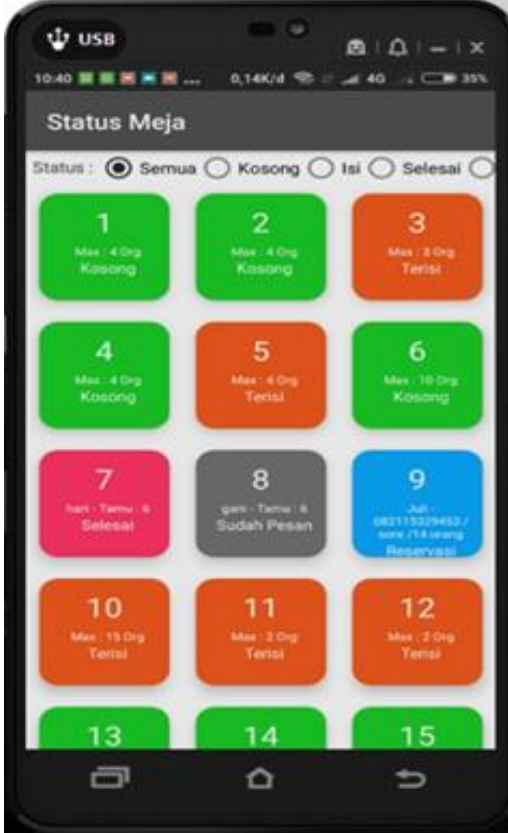

Gambar 9. Form Status Meja Aplikasi Android

3. Form Rubah Status Meja akan muncul ketika user sudah memilih meja yang akan dirubah status nya.

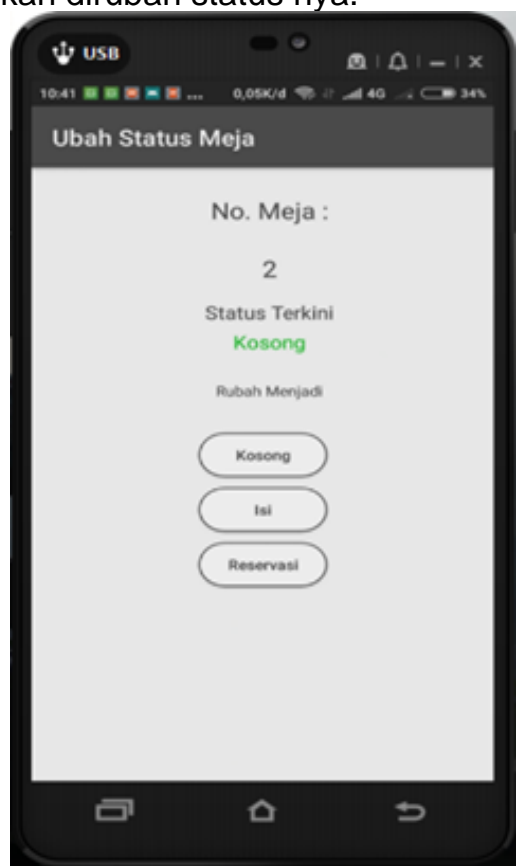

Gambar 10. Form Rubah Status Meja Aplikasi Android

4. Transaksi Order diinput ketika pelanggan sudah memutuskan apa saja yang akan dipesan, jika sudah selesai user akan mengirim pesanan tersebut ke bagian dapur dengan cara tap tombol "KIRIM KE DAPUR". 


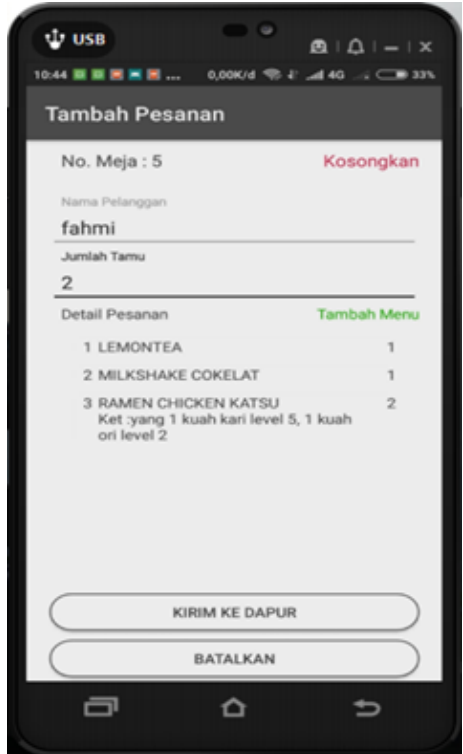

Gambar 11. Form Input Transaksi Order

5. Aplikasi AndroidKetika user memilih "Tambah Menu" pada form input transaksi order, maka sistem akan menampilkan daftar menu untuk dipilih menu apa saja yang akan dipesan.

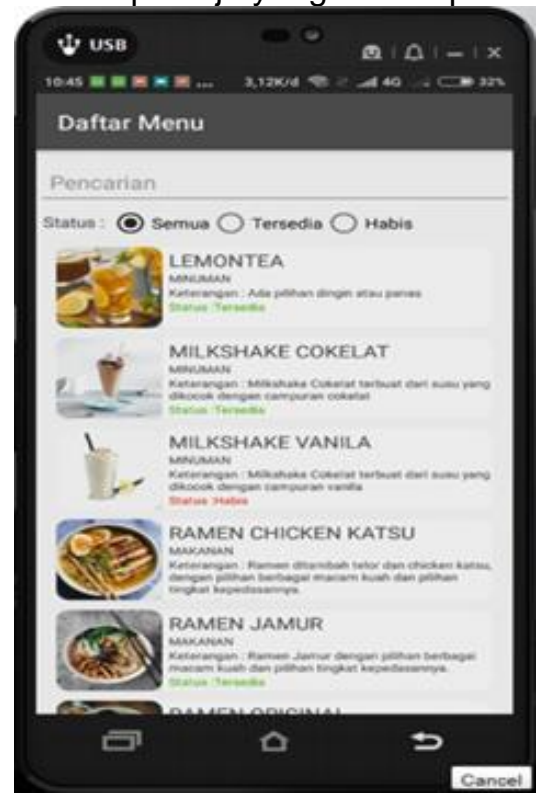

Gambar 12. Form Daftar Menu Aplikasi

$$
\text { Android }
$$

6. Status Dapur adalah tampilan ketika user dengan jenis koki melakukan login dan memilih menu aktivitas. Form ini akan menampilkan data menu yang harus ditindak lanjuti oleh koki.

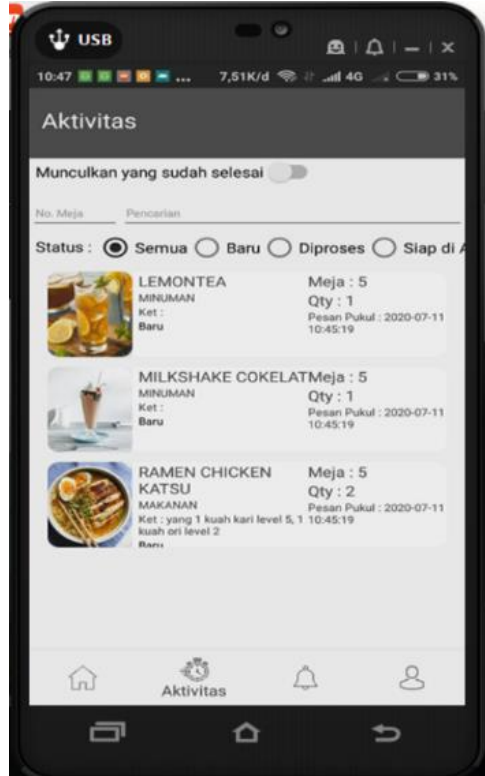

Gambar 13. Form Status Dapur Aplikasi Android

\subsection{Pengujian Sistem}

Pengujian yang dilakukan pada penelitian ini menggunakan metode pengujian blackbox. Black-Box Testing merupakan Teknik pengujian perangkat lunak yang berfokus pada spesifikasi fungsional dari perangkat lunak (Jaya, 2018).

Pengujian Aplikasi Desktop

Tabel 1. Pengujian Aplikasi Desktop

\begin{tabular}{|c|c|c|c|c|}
\hline No & Kasus & $\begin{array}{c}\text { Sekenari } \\
0 \\
\text { Pengujia } \\
n\end{array}$ & $\begin{array}{c}\text { Hasil } \\
\text { Yang } \\
\text { Diharapk } \\
\text { an } \\
\end{array}$ & Hasil \\
\hline \multicolumn{5}{|c|}{ Form Login } \\
\hline 1 & \begin{tabular}{|l|} 
Klik \\
tomb \\
ol \\
masu \\
k
\end{tabular} & $\begin{array}{l}\text { Mengisika } \\
\mathrm{n} \text { user id } \\
\text { dan } \\
\text { password } \\
\text { kemudian } \\
\text { mengklik } \\
\text { masuk }\end{array}$ & $\begin{array}{l}\text { Berhasil } \\
\text { masuk } \\
\text { kedalam } \\
\text { sistem dan } \\
\text { menampilk } \\
\text { an form } \\
\text { main menu }\end{array}$ & Sukses \\
\hline 2 & $\begin{array}{l}\text { Klik } \\
\text { tomb } \\
\text { ol } \\
\text { masu } \\
\mathrm{k}\end{array}$ & $\begin{array}{l}\text { Tidak } \\
\text { mengisi } \\
\text { user id } \\
\text { dan } \\
\text { password }\end{array}$ & $\begin{array}{l}\text { Muncul } \\
\text { pesan user } \\
\text { id atau kata } \\
\text { sandi salah }\end{array}$ & Sukses \\
\hline 3 & \begin{tabular}{|l|} 
Klik \\
tomb \\
ol \\
masu \\
$\mathrm{k}$
\end{tabular} & $\begin{array}{l}\text { Mengisi } \\
\text { user id } \\
\text { dan } \\
\text { password } \\
\text { tidak } \\
\text { sesuai } \\
\text { dengan } \\
\text { yang ada } \\
\text { di sistem }\end{array}$ & $\begin{array}{l}\text { Muncul } \\
\text { pesan user } \\
\text { id dan } \\
\text { password } \\
\text { salah }\end{array}$ & pukses \\
\hline
\end{tabular}




\begin{tabular}{|c|c|c|c|c|}
\hline \multicolumn{5}{|c|}{ Form Master } \\
\hline 1 & $\begin{array}{l}\text { Klik } \\
\text { tomb } \\
\text { ol } \\
\text { tamb } \\
\text { ah }\end{array}$ & $\begin{array}{l}\text { Munculka } \\
\mathrm{n} \text { form } \\
\text { inputan, } \\
\text { isi semua } \\
\text { field dan } \\
\text { klik } \\
\text { tombol } \\
\text { simpan }\end{array}$ & $\begin{array}{l}\text { Munculkan } \\
\text { pesan data } \\
\text { berhasil } \\
\text { disimpan } \\
\text { dan data } \\
\text { harus } \\
\text { tersimpan } \\
\text { ke } \\
\text { database }\end{array}$ & Suks \\
\hline 2 & $\begin{array}{l}\text { Klik } \\
\text { tomb } \\
\text { ol edit }\end{array}$ & $\begin{array}{l}\text { Munculka } \\
\mathrm{n} \text { form } \\
\text { edit, ubah } \\
\text { data dan } \\
\text { klik } \\
\text { tombol } \\
\text { simpan }\end{array}$ & $\begin{array}{l}\text { Munculkan } \\
\text { pesan data } \\
\text { berhasil } \\
\text { diubah dan } \\
\text { data di } \\
\text { database } \\
\text { berubah }\end{array}$ & \\
\hline 3 & $\begin{array}{l}\text { Klik } \\
\text { tomb } \\
\text { ol } \\
\text { aktiva } \\
\text { si }\end{array}$ & $\begin{array}{l}\text { Memilih } \\
\text { data yang } \\
\text { akan } \\
\text { diaktifan } \\
\text { atau di } \\
\text { non } \\
\text { aktifkan } \\
\text { kemudian } \\
\text { klik } \\
\text { tombol } \\
\text { aktivasi }\end{array}$ & $\begin{array}{l}\text { Muncul } \\
\text { pesan data } \\
\text { berhasil di } \\
\text { aktifkan } \\
\text { atau dinon } \\
\text { aktifkan }\end{array}$ & \\
\hline 4 & $\begin{array}{l}\text { Klik } \\
\text { tomb } \\
\text { ol } \\
\text { cetak }\end{array}$ & $\begin{array}{l}\text { Load data } \\
\text { kemudian } \\
\text { pilih } \\
\text { tombol } \\
\text { cetak }\end{array}$ & $\begin{array}{l}\text { Munculkan } \\
\text { tampilan } \\
\text { cetak rekap }\end{array}$ & \\
\hline 5 & $\begin{array}{l}\text { Klik } \\
\text { tomb } \\
\text { ol } \\
\text { ekspo } \\
\text { r }\end{array}$ & $\begin{array}{l}\text { Load data } \\
\text { kemudian } \\
\text { pilih } \\
\text { tombol } \\
\text { ekspor }\end{array}$ & $\begin{array}{l}\text { Muncul } \\
\text { save dialog } \\
\text { untuk lokasi } \\
\text { penyimpan } \\
\text { an file excel }\end{array}$ & \\
\hline \multicolumn{5}{|c|}{ Form Transaksi } \\
\hline 1 & $\begin{array}{l}\text { Klik } \\
\text { tomb } \\
\text { ol } \\
\text { tamb } \\
\text { ah }\end{array}$ & $\begin{array}{l}\text { Munculka } \\
\mathrm{n} \text { form } \\
\text { inputan, } \\
\text { isi semua } \\
\text { field dan } \\
\text { klik } \\
\text { tombol } \\
\text { simpan }\end{array}$ & $\begin{array}{l}\text { Munculkan } \\
\text { pesan data } \\
\text { berhasil } \\
\text { disimpan } \\
\text { dan data } \\
\text { harus } \\
\text { tersimpan } \\
\text { ke } \\
\text { database }\end{array}$ & Sulo \\
\hline 2 & $\begin{array}{l}\text { Klik } \\
\text { tomb } \\
\text { ol edit }\end{array}$ & $\begin{array}{l}\text { Munculka } \\
\mathrm{n} \text { form } \\
\text { edit, ubah } \\
\text { data dan } \\
\text { klik } \\
\text { tombol } \\
\text { simpan }\end{array}$ & $\begin{array}{l}\text { Munculkan } \\
\text { pesan data } \\
\text { berhasil } \\
\text { diubah dan } \\
\text { data di } \\
\text { database } \\
\text { berubah }\end{array}$ & rse \\
\hline
\end{tabular}

\begin{tabular}{|c|c|c|c|c|}
\hline 3 & $\begin{array}{l}\text { Klik } \\
\text { tomb } \\
\text { ol } \\
\text { hapu } \\
\mathrm{s}\end{array}$ & $\begin{array}{l}\text { Memilih } \\
\text { data yang } \\
\text { akan } \\
\text { dihapus }\end{array}$ & $\begin{array}{l}\text { Muncul } \\
\text { pesan data } \\
\text { berhasil di } \\
\text { hapus, dan } \\
\text { data } \\
\text { menghilang } \\
\text { di form } \\
\text { rekap }\end{array}$ & Sukses \\
\hline 4 & $\begin{array}{l}\text { Klik } \\
\text { tomb } \\
\text { ol } \\
\text { cetak }\end{array}$ & $\begin{array}{l}\text { Load data } \\
\text { kemudian } \\
\text { pilih } \\
\text { tombol } \\
\text { cetak }\end{array}$ & $\begin{array}{l}\text { Munculkan } \\
\text { tampilan } \\
\text { cetak rekap }\end{array}$ & Sukses \\
\hline 5 & $\begin{array}{l}\text { Klik } \\
\text { tomb } \\
\text { ol } \\
\text { ekspo } \\
\text { r }\end{array}$ & $\begin{array}{l}\text { Load data } \\
\text { kemudian } \\
\text { pilih } \\
\text { tombol } \\
\text { ekspor }\end{array}$ & $\begin{array}{l}\text { Muncul } \\
\text { save dialog } \\
\text { untuk lokasi } \\
\text { penyimpan } \\
\text { an file excel }\end{array}$ & Sukses \\
\hline \multicolumn{5}{|c|}{ Form Laporan } \\
\hline 1 & $\begin{array}{l}\text { Load } \\
\text { data } \\
\text { sesua } \\
\text { i filter } \\
\text { terpili } \\
\text { h }\end{array}$ & $\begin{array}{l}\text { Memilih } \\
\text { filter klik } \\
\text { tombol } \\
\text { load }\end{array}$ & $\begin{array}{l}\text { Munculkan } \\
\text { data sesuai } \\
\text { filter }\end{array}$ & Sukses \\
\hline 2 & $\begin{array}{l}\text { Klik } \\
\text { tomb } \\
\text { ol } \\
\text { cetak }\end{array}$ & $\begin{array}{l}\text { Load data } \\
\text { kemudian } \\
\text { pilih } \\
\text { tombol } \\
\text { cetak }\end{array}$ & $\begin{array}{l}\text { Munculkan } \\
\text { tampilan } \\
\text { cetak rekap }\end{array}$ & Sukses \\
\hline 3 & $\begin{array}{l}\text { Klik } \\
\text { tomb } \\
\text { ol } \\
\text { ekspo } \\
\text { r }\end{array}$ & $\begin{array}{l}\text { Load data } \\
\text { kemudian } \\
\text { pilih } \\
\text { tombol } \\
\text { ekspor }\end{array}$ & $\begin{array}{l}\text { Muncul } \\
\text { save dialog } \\
\text { untuk lokasi } \\
\text { penyimpan } \\
\text { an file } \\
\text { excel, } \\
\text { sistem } \\
\text { melakukan } \\
\text { proses } \\
\text { ekspor data }\end{array}$ & Sukses \\
\hline 4 & $\begin{array}{l}\text { Klik } \\
\text { tomb } \\
\text { ol } \\
\text { yang } \\
\text { tidak } \\
\text { dapat } \\
\text { diaks } \\
\text { es } \\
\text { oleh } \\
\text { user } \\
\text { yang } \\
\text { seda } \\
\text { ng } \\
\text { login }\end{array}$ & $\begin{array}{l}\text { Mencoba } \\
\text { memilih } \\
\text { tombol } \\
\text { yang user } \\
\text { login tidak } \\
\text { memiliki } \\
\text { aksesnya }\end{array}$ & $\begin{array}{l}\text { Muncul } \\
\text { pesan } \\
\text { "Anda tidak } \\
\text { memiliki } \\
\text { autorisasi } \\
\text { pada fungsi } \\
\text { ini." }\end{array}$ & Sukses \\
\hline
\end{tabular}


Pengujian Aplikasi Android

Tabel 2. Pengujian Aplikasi Android

\begin{tabular}{|c|c|c|c|c|}
\hline No & Kasus & $\begin{array}{l}\text { Sekenario } \\
\text { Pengujian }\end{array}$ & $\begin{array}{c}\text { Hasil Yang } \\
\text { Diharapka } \\
\mathbf{n}\end{array}$ & $\begin{array}{c}\text { Hasi } \\
\text { I }\end{array}$ \\
\hline \multicolumn{5}{|c|}{ Form Login } \\
\hline 1 & $\begin{array}{l}\text { Tap } \\
\text { tomb } \\
\text { ol } \\
\text { masu } \\
\mathrm{k}\end{array}$ & $\begin{array}{l}\text { Mengisikan } \\
\text { user id dan } \\
\text { password } \\
\text { kemudian } \\
\text { mengklik } \\
\text { masuk }\end{array}$ & $\begin{array}{l}\text { Berhasil } \\
\text { masuk } \\
\text { kedalam } \\
\text { sistem dan } \\
\text { menampilk } \\
\text { an form } \\
\text { main menu }\end{array}$ & $\begin{array}{c}\text { Sukse } \\
\text { s }\end{array}$ \\
\hline 2 & $\begin{array}{l}\text { Tap } \\
\text { tomb } \\
\text { ol } \\
\text { masu } \\
\mathrm{k} \\
\end{array}$ & $\begin{array}{l}\text { Tidak } \\
\text { mengisi } \\
\text { user id dan } \\
\text { password }\end{array}$ & $\begin{array}{l}\text { Muncul } \\
\text { pesan user } \\
\text { id atau } \\
\text { kata sandi } \\
\text { salah }\end{array}$ & $\begin{array}{c}\text { Sukse } \\
\text { s }\end{array}$ \\
\hline 3 & $\begin{array}{l}\text { Tap } \\
\text { tomb } \\
\text { ol } \\
\text { masu } \\
\mathrm{k}\end{array}$ & $\begin{array}{l}\text { Mengisi } \\
\text { user id dan } \\
\text { password } \\
\text { tidak sesuai } \\
\text { dengan } \\
\text { yang ada di } \\
\text { sistem }\end{array}$ & $\begin{array}{l}\text { Muncul } \\
\text { pesan user } \\
\text { id dan } \\
\text { password } \\
\text { salah }\end{array}$ & $\begin{array}{c}\text { Sukse } \\
\text { s }\end{array}$ \\
\hline \multicolumn{5}{|c|}{ Form Daftar Menu } \\
\hline 1 & $\begin{array}{l}\text { Meru } \\
\text { bah } \\
\text { statu } \\
\text { s } \\
\text { menu }\end{array}$ & $\begin{array}{l}\text { Pilih daftar } \\
\text { menu, } \\
\text { muncul } \\
\text { form status } \\
\text { menu, pilih } \\
\text { menu yang } \\
\text { mau } \\
\text { dirubah } \\
\text { statusnya, } \\
\text { tap tombol } \\
\text { habis / } \\
\text { tersedia } \\
\end{array}$ & $\begin{array}{l}\text { Sistem } \\
\text { akan } \\
\text { menampilk } \\
\text { an } \\
\text { perubahan } \\
\text { status } \\
\text { pada form } \\
\text { daftar } \\
\text { menu }\end{array}$ & $\begin{array}{c}\text { Sukse } \\
\text { s }\end{array}$ \\
\hline \multicolumn{5}{|c|}{ Form Status Meja } \\
\hline 1 & $\begin{array}{l}\text { Peng } \\
\text { guna } \\
\text { an } \\
\text { filter } \\
\text { statu } \\
\text { s }\end{array}$ & $\begin{array}{l}\text { Pilih status } \\
\text { meja, } \\
\text { memilih } \\
\text { status } \\
\text { menu yang } \\
\text { akan } \\
\text { ditampilkan }\end{array}$ & $\begin{array}{l}\text { Sistem } \\
\text { menampilk } \\
\text { an data } \\
\text { meja yang } \\
\text { statusnya } \\
\text { sesuai filter } \\
\text { yang } \\
\text { digunakan }\end{array}$ & nou \\
\hline 2 & $\begin{array}{l}\text { Meru } \\
\text { bah } \\
\text { statu } \\
\text { s } \\
\text { meja }\end{array}$ & $\begin{array}{l}\text { Pilih meja, } \\
\text { muncul } \\
\text { form rubah } \\
\text { status } \\
\text { meja, pilih } \\
\text { status } \\
\text { barunya }\end{array}$ & $\begin{array}{l}\text { Munculkan } \\
\text { form rubah } \\
\text { status, } \\
\text { ketika } \\
\text { selesai } \\
\text { pilih status } \\
\text { barunya, } \\
\text { sistem } \\
\text { akan }\end{array}$ & $\begin{array}{c}\text { Sukse } \\
\text { s }\end{array}$ \\
\hline
\end{tabular}

\begin{tabular}{|c|c|c|c|c|}
\hline & & & $\begin{array}{l}\text { menampilk } \\
\text { an form } \\
\text { data meja. }\end{array}$ & \\
\hline 3 & $\begin{array}{l}\text { Memi } \\
\text { lih } \\
\text { meja } \\
\text { yang } \\
\text { statu } \\
\text { snya } \\
\text { terisi }\end{array}$ & $\begin{array}{l}\text { Pilih meja } \\
\text { dengan } \\
\text { status terisi }\end{array}$ & $\begin{array}{l}\text { Pilih meja } \\
\text { dengan } \\
\text { statusnya } \\
\text { terisi, } \\
\text { sistem } \\
\text { akan } \\
\text { menampilk } \\
\text { an form } \\
\text { input } \\
\text { transaksi } \\
\text { order }\end{array}$ & $\begin{array}{c}\text { Sukse } \\
\text { s }\end{array}$ \\
\hline \multicolumn{5}{|c|}{ Form Input Transaksi Order } \\
\hline 1 & $\begin{array}{l}\text { Tamb } \\
\text { ah } \\
\text { pesa } \\
\text { nan }\end{array}$ & $\begin{array}{l}\text { Pilih meja } \\
\text { yang } \\
\text { statusnya } \\
\text { terisi, input } \\
\text { semua } \\
\text { datanya \& } \\
\text { pilih menu } \\
\text { - menu } \\
\text { yang akan } \\
\text { dipesan, } \\
\text { tap tombol } \\
\text { kirim ke } \\
\text { dapur }\end{array}$ & $\begin{array}{l}\text { Ketika pilih } \\
\text { tombol } \\
\text { kirim ke } \\
\text { dapur, } \\
\text { pesanan } \\
\text { akan } \\
\text { diteruskan } \\
\text { ke bagian } \\
\text { dapur }\end{array}$ & jukses \\
\hline 2 & $\begin{array}{l}\text { Mem } \\
\text { batal } \\
\text { kan } \\
\text { trans } \\
\text { aksi }\end{array}$ & $\begin{array}{l}\text { Tap tombol } \\
\text { "Batalkan" }\end{array}$ & $\begin{array}{l}\text { Sistem } \\
\text { akan } \\
\text { membatalk } \\
\text { an } \\
\text { transaksi } \\
\text { tersebut }\end{array}$ & $\begin{array}{c}\text { Sukse } \\
\text { s }\end{array}$ \\
\hline \multicolumn{5}{|c|}{ Form Status Dapur } \\
\hline 1 & $\begin{array}{l}\text { Peng } \\
\text { guna } \\
\text { an } \\
\text { filter } \\
\text { statu } \\
\text { s }\end{array}$ & $\begin{array}{l}\text { Mengisikan } \\
\text { filter dan } \\
\text { memilih } \\
\text { filter status }\end{array}$ & $\begin{array}{l}\text { Sistem } \\
\text { menampilk } \\
\text { an data } \\
\text { menu yang } \\
\text { dipesan } \\
\text { oleh } \\
\text { pelanggan }\end{array}$ & pukses \\
\hline 2 & $\begin{array}{l}\text { Meru } \\
\text { bah } \\
\text { statu } \\
\text { s } \\
\text { menu } \\
\text { yang } \\
\text { dipes } \\
\text { an }\end{array}$ & $\begin{array}{l}\text { Pilih menu } \\
\text { yang akan } \\
\text { dirubah } \\
\text { statusnya }\end{array}$ & $\begin{array}{l}\text { Sistem } \\
\text { akan } \\
\text { merubah } \\
\text { status } \\
\text { menu } \\
\text { tersebut, } \\
\text { dan jika } \\
\text { statusnya } \\
\text { berubah } \\
\text { jadi "Siap", } \\
\text { sistem } \\
\text { akan } \\
\text { memberika } \\
\text { n notifikasi }\end{array}$ & $\begin{array}{c}\text { Sukse } \\
\text { s }\end{array}$ \\
\hline
\end{tabular}




\begin{tabular}{|c|c|c|c|c|}
\hline & & & $\begin{array}{l}\text { kepada } \\
\text { pelayan }\end{array}$ & \\
\hline \multicolumn{5}{|c|}{ Aktivitas Pelayan } \\
\hline 1 & $\begin{array}{l}\text { Peng } \\
\text { guna } \\
\text { an } \\
\text { filter } \\
\text { statu } \\
\text { s }\end{array}$ & $\begin{array}{l}\text { Mengisikan } \\
\text { filter dan } \\
\text { memilih } \\
\text { filter status }\end{array}$ & $\begin{array}{l}\text { Sistem } \\
\text { menampilk } \\
\text { an data } \\
\text { transaksi } \\
\text { order yang } \\
\text { diinput oleh } \\
\text { pelayan } \\
\text { tersebut }\end{array}$ & juks \\
\hline 2 & $\begin{array}{l}\text { Melih } \\
\text { at } \\
\text { detail } \\
\text { trans } \\
\text { aksi } \\
\text { order }\end{array}$ & $\begin{array}{l}\text { Pilih } \\
\text { transaksi } \\
\text { yang akan } \\
\text { dilihat } \\
\text { detailnya }\end{array}$ & $\begin{array}{l}\text { Sistem } \\
\text { akan } \\
\text { menampilk } \\
\text { an } \\
\text { halaman } \\
\text { status } \\
\text { dapur, } \\
\text { yang } \\
\text { sudah } \\
\text { terfilter } \\
\text { hanya } \\
\text { pesanan } \\
\text { dari } \\
\text { transaksi } \\
\text { yang dipilih }\end{array}$ & $\begin{array}{c}\text { Suks } \\
\text { S }\end{array}$ \\
\hline
\end{tabular}

\section{Kesimpulan Pengujian}

Pada pengujian ini berdasarkan rincian dari Tabel Pengujian Aplikasi Desktop dan Tabel Pengujian Aplikasi Android. Maka penulis menyimpulkan bahwa semua pengujian berdasarkan masing - masing kasus yang diuji telah sukses dilakukan. Sistem mampu merespon semua perintah sesuai dengan harapan penguji.

\section{Kesimpulan}

Dari aplikasi yang telah dibuat maka penulis menyimpulkan bahwa :

1. Aplikasi dibangun di dua platform yang berbeda yaitu aplikasi desktop yang berjalan di Microsoft Windows dan aplikasi mobile yang berjalan di Android. Sehingga pengguna lebih nyaman dalam mengoperasikannya.

2. Menambahkan beberapa fitur yang mampu mempermudah dan meningkatkan kualitas pelayanan dalam pengelolaan restoran, seperti: Menambahkan fasilitas status meja, yang berfungsi untuk mengetahui meja mana saja yang masih kosong, yang harus dibereskan, yang sudah ada reservasi atau yang sudah terisi tapi belum melakukan pemesanan; Kelola user yang aksesnya lebih mendetail, adanya hak akses per menu dan ada juga hak ases per fitur yang ada di menu, misalnya untuk kasir diperbolehkan input faktur jual, tapi tidak dibolehkan untuk perubahaan data faktur jual; Menambahkan master kas \& bank, sebagai pencatatan saldo keuangan pada data kas / bank yang digunakan; Menambahkan transaksi keluar / masuk uang, transaksi ini untuk pencatatan keuangan selain penjualan; Faktur Jual bisa berdasarkan pesanan dari pengunjung yang makan ditempat atau pembelian untuk dibawa pulang; Penambahan grafik penjulan dan grafik ranking menu; Penambahan laporan baru, yaitu laporan mutasi kas bank, laporan penjualan, dan laporan ranking penjualan; Penambahan fitur untuk ekspor data ke format excel; Penambahan fitur untuk cetak rekap dan cetak transaksi.

\section{Referensi}

Arisantoso, A. S. H. (2019). Fakultas Teknik - Universitas Muria Kudus. Prosiding SNATIF Ke-6 Tahun 2019, 96-101. https://doi.org/10.2298/PAN0903301G

developer.android.com. (2020). Android Studio. Www.Developer.Android.Com. developer.android.com/studio/intro?hl= id

embarcadero.com. (2020). Delphi. Www.Embarcadero.Com. https://www.embarcadero.com/product s/delphi

Febriyansyah, R., Bijaksana, A., Negara, P., \& Safriadi, N. (2017). Rancang Bangun Aplikasi Pemesanan Menu di Restoran Berbasis Web. 5(3), 1-5.

Http://edel.staff.unja.ac.id. (2016). Pengertian MySQL.

Http://Edel.Staff.Unja.Ac.Id. http://edel.staff.unja.ac.id/blog/artikel/P engertian-MySQL.html

Hutahaean, J. (2015). Konsep Sistem Informasi. In Jurnal Administrasi Pendidikan UPI (Vol. 3, Issue 1). Deepublish.

Jaya, T. S. (2018). Pengujian Aplikasi dengan Metode Blackbox Testing Boundary Value Analysis (Studi Kasus: Kantor Digital Politeknik Negeri Lampung). Jurnal Informatika Pengembangan IT (JPIT), 3(2), 45-46. https://doi.org/10.30591/jpit.v3i1.647

Junianto, E., \& Zuhdi, M. Z. (2018). Penerapan Metode Palette untuk 
Menentukan Warna Dominan dari Sebuah Penerapan Metode Palette untuk Menentukan Warna Dominan dari Sebuah Gambar Berbasis Android. April.

https://doi.org/10.31311/ji.v5i1.2740

Lockhart, J., Smith, A., \& Allen, R. (2020). Slim Framework. Www.Slimframework.Com.

https://www.slimframework.com/docs/v $4 / /$

Rakhmah, S. N., Reza, R., \& Novel, K. (2019). Aplikasi Delivery Order Makanan Dan Minuman Berbasis Web Pada Restoran Mang Kabayan. Jurnal Teknika, 11(2), 1109. https://doi.org/10.30736/jt.v11i2.341

Setiawan, R. (2017). Sistem Operasi. Seribu Bintang.

https://books.google.co.id/books?id=rq g-DwAAQBAJ

Sofyan, A. P., Arifin, T., \& Fauzi, A. (2019). APLIKASI PEMESANAN MAKANAN MINUMAN BEBRBASIS ANDROID PADA RUMAH MAKAN SUSHI ZEN RAMEN.

Unit Laboratorium Fakultas IImu Terapan. (2017). Mengenal Berbagai Jenis Software Database. Https://Fit.Labs.Telkomuniversity.Ac.ld/ .https://fit.labs.telkomuniversity.ac.id/m engenal-berbagai-jenis-software-

database/ 